\title{
Correction to: Effect of Preoperative Treatment on the Performance of Predictive Nomograms in Primary Retroperitoneal Sarcoma
}

\author{
Deanna Ng, MBBS $S^{1,2,3,4}$, David P. Cyr, MD, MSe ${ }^{1,2,3,4}$, Sally M. Burtenshaw, MSc ${ }^{1,2}$, Dario Callegaro, MD ${ }^{5}$, \\ Alessandro Gronchi, $\mathrm{MD}^{5}$, David Shultz, $\mathrm{MD}^{6}$, Savtaj Brar, MD, MSc ${ }^{1,2}$, Peter Chung, MD ${ }^{6}$, \\ Rebecca A. Gladdy, MD, PhD ${ }^{1,2,4}$, Charles Catton, $\mathrm{MD}^{6}$, and Carol J. Swallow, MD, PhD ${ }^{1,2,3,4}$ \\ ${ }^{1}$ Department of Surgical Oncology, Princess Margaret Cancer Centre/Mount Sinai Hospital, Toronto, ON, Canada; \\ ${ }^{2}$ Department of Surgery, University of Toronto, Toronto, ON, Canada; ${ }^{3}$ Institute of Medical Science, University of \\ Toronto, Toronto, Canada; ${ }^{4}$ Lunenfeld-Tanenbaum Research Institute, Sinai Health System, Toronto, Canada; \\ ${ }^{5}$ Department of Surgery, Fondazione IRCCS Istituto Nazionale dei Tumori, Milan, Italy; ${ }^{6}$ Princess Margaret Cancer \\ Centre, Department of Radiation Oncology, University of Toronto, Toronto, ON, Canada
}

\section{CORRECTION TO: ANN SURG ONCOL HTTPS://D} OI.ORG/10.1245/S10434-021-11156-X

In the original online version of this article there were errors in Table 2 and Fig. 3. The original article was corrected.
Publisher's Note Springer Nature remains neutral with regard to jurisdictional claims in published maps and institutional affiliations.

The original article can be found online at https://doi.org/10.1245/ s10434-021-11156-x.

(C) Society of Surgical Oncology 2022

Published Online: 24 January 2022

C. Catton, MD

e-mail: charles.catton@rmp.uhn.ca 